\title{
Photon Information Processing
}

DOI: $10.3938 /$ PhiT. 23. 038

\section{함 병 승}

\section{Photon Information Processing}

\section{Byoung Seung HAM}

Since the advent of the electronic transistor in 1947 at Bell Laboratory, human history has been phase shifted from the industrial era toward the information era. Since the internet opened in the 1990s, anyone has virtually been able to access anybody anytime, anywhere. Unfortunately, due to the limits on the speeds of electronic devices, the so-called "end of Moor's law," the electronic evolution has already come to an end. To make a quantum jump toward a ubiquitous society in the future, many researchers have studied photon information processing over the last several decades. However, most studies have been limited by less-matured technologies. Here, strong photon candidates that can compete with electronic gadgets and allow human civilization to continue its progress are reviewed.

\section{서 론}

1947년 반도체 트랜지스터의 발명으로 인류역사는 문명의 대 변혁기를 맞는다. 바로 컴퓨터의 등장이다. 이로 인해 기계 문명은 급속히 전자문명으로 대체되어 갔고, 1990년대 인터넷 과 결합하여 인류역사상 상상할 수 없는 비약적인 문명의 진 보가 이루어져, 2000년대에는 공간의 제약을 극복하고 실시간 통신이 가능한 $\mathrm{SNS}$ (사회망시스템)의 온라인 가상 사회를 열었 다. 그러나 유비쿼터스 사회 진화는 무어의 법칙으로 일컬어지

\section{저자약력}

함병승 교수는 1995년 Wayne State University에서 전기공학으로 공학 박사 학위를 받고, 미국 MIT, Hanscom공군연구소, 한국전자통신연구원, 인하대학교 등에서 연구하였다. 현재 광주과학기술원(GIST) 정보통신공학부 특훈교수로 재직 중이며, 광양자정보처리센터장을 맡고 있다. (bham@gist.ac.kr)
는 전자 하드웨어 진화 중단으로 말미암아 그 초입에도 들어 서지 못한 채 답보상태이다. 물론 전자 하드웨어와 통신 인프 라의 제약은 애플의 스마트폰으로 일컬어지는 소프트웨어의 개 선과 적용이라는 혁신이 있었음에도 불구하고, 소프트웨어 분 야 역시 점차 그 한계점에 가까이 다가서고 있음도 주지의 사 실이다. 이를 해결하고 어느 곳에서나 아무 기기로나 인터넷 가상세계에 접속 가능한 유비쿼터스 사회 완결은 늘 그래왔듯 디지털 정보처리에 있어 혁명적 사건이 일어나지 않는 한 요 원하다. 아마도 그것은 현재 정보처리 방식과는 완전히 다른 새로운 방식, 예를 들면 비선형양자광학과 퀀텀 인터넷이 될지 도 모른다. 본 논고에서는 지금까지 발표된 논문을 기초로 하 여 간단하게 포톤정보처리에 관해 살펴보기로 한다.

\section{본 론}

\section{1. 광정보처리}

1980년대 광섬유 개발은 이전 통신 시스템으로는 상상도 할 수 없는 $100 \mathrm{THz}$ 대역의 광통신망 세계를 열었다. 공간적으 로 멀리 떨어진 모든 통신 기기들은 기본적으로 광통신 백본 망에 접속되어 공간적 제약을 넘어 빛의 속도로 세계 어느 곳 에서든지 실시간 통신이 가능하다. 그러나 통신용량이 기하급 수적으로 증가함에 따라 하드웨어의 처리능력은 한계에 다다르 고, 이로 인해 데이터 처리 지연은 필연적으로 발생한다. 예를 들면 백만 명 인터넷 동시접속의 경우(서버로 향하는 1:N 포 함; 1 인 $1 \mathrm{Mbps}$ 경위, 시간지연 없는 통신을 소화하기 위해 서는 이상적으로는 $100 \mathrm{THz}$ 대역을 갖는 광스위치/광라우터 와 광버퍼 메모리가 필요하다. 그러나 현실적으로 이를 만족하 는 광소자는 아직 존재하지 않는다. 설령 이들 광소자가 광통 신망에 적용된다 하더라도 이를 지원하기 위한 컴퓨터 처리속 도 역시 이들과 비슷해야 하는데, 현재 전자컴퓨터의 $\mathrm{CPU}$ 속 도는 겨우 $4 \mathrm{GHz}$ 여서, 아마도 슈퍼컴이 필요하게 될지도 모르 겠다. 현실적인 측면을 고려하더라도 유비쿼터스 사회 진입을 위한 인프라를 구성하기 위해서는 $\mathrm{THz}$ 이상의 대역폭을 가진 
능동 광소자와 이를 지원할 컴퓨터 즉 광컴퓨터의 확보가 이 상적인 하부구조의 기본조건이 된다. 결국 새로운 물리학/공학 패러다임이 나오지 않는 한 유비쿼터스 사회는 허망한 구호가 된다.

\section{(1) $\mathrm{THz}$ 광스위치}

위에서 언급한 문제를 해결하고자 2000년 과학기술부 창의 적연구진흥사업으로 ' $\mathrm{THz}$ 광스위치 연구개발사업'이 ETRI에서 수행되었다. ${ }^{[1]}$ 1990년대 초반, 원자물리학이 역사의 무대 뒤로 사라질 위기에 처했을 무렵, 전자기유도투과(EIT)라는 비선형양 자광학의 새로운 분야가 국제 양자광학계에 혜성같이 등장하였 는데, ${ }^{[2]}$ 이로 말미암아 2000년대에는 느린 빛과 ${ }^{[3]}$ 양자메모리 ${ }^{[4]}$ 분야가 탄생하게 된다. 일반적으로 비선형광학에서는 광흡수가 최고인 곳에서 비선형계수도 가장 높게 된다. ${ }^{[5]}$ 그러나 생성된 섞음파장 재흡수 역시 최고이기 때문에, 이를 피하고자 비선형 효율이 낮아지는 비공진주파수 영역을 택할 수밖에 없는데, EIT는 바로 이 문제를 해결한 것이다. 즉, 공진주파수에서 양 자간섭상쇄로 인하여 광흡수가 사라져, 비선형효율은 비약적으 로 커지게 됨이 증명되었고, ${ }^{[6]}$ 이 원리를 반도체 매질을 이용 초고속 광스위칭에 적용하고자 한 것이 위의 ' $\mathrm{THz}$ 광스위칭 연구개발사업이다. 아쉽게도, 이 사업은 ETRI의 행정지원 미 비와 연구단장의 이직으로 3년만에 중단되게 되었으나, 이후 국제적으로 느린 빛을 광스위칭에 적용하려는 시도가 광범위하 게 일어나, 광결정과 ${ }^{[7]}$ 반도체 화합물, ${ }^{[8]}$ 그리고 심지어 표면 플라즈몬 영역에서까지 ${ }^{[9]}$ 활발한 연구활동이 지금까지 계속되 고 있다. 2014년 8월 중국에서 개최된 PIERS2014에 따르면, 최근 나노포토닉스와 양자광학의 결합이 초고속/고효율 양자광 소자 출현을 앞당기게 하고 있다.

\section{(2) $\mathrm{THz}$ 광로직}

1990년대 중반부터 KIST '차세대포토닉스 연구개발사업단' 에서는 과학기술부 지원으로 반도체증폭기(SOA) 기반 광로직 사업을 수행하여 NAND, NOR 등 $100 \mathrm{GHz}$ 이상의 광로직을 증명하였다. ${ }^{[10]}$ 이러한 광로직 연구는 1990년 이래 이십여 년 간 전 세계적으로 광범위하게 수행되었는데, 여기에는 1980년 대 광컴퓨팅 연구개발에 그 기원이 있었다. 문제는 실용화인 데, 가장 유력하게 검토되었던 $\mathrm{SOA}$ 기반 광로직의 경우, $\mathrm{SOA}$ 단위소자 크기와 소비전력을 고려할 때, 예를 들면 백만 개 $\mathrm{SOA}$ 트랜지스터로 구성된 386급 광CPU(1990년대 초)를 구성 하는데도, $10 \mathrm{~m}^{2}$ 의 소자크기와 $100 \mathrm{~kW}$ 의 전력이 필요하는 등 현실적인 한계가 있었다. ${ }^{[1]}$ 2006년, 이러한 기존의 집적화 불능이란 광로직 한계를 극복하고자 제안된 것이 느린 빛 기 반의 '유니버설 광컴퓨팅' 연구이다. ${ }^{[12]}$ 이 사업은 반도체 디지
털 광로직 연구와 순수 양자 정보처리만을 위한 양자메모리 연구로 구성되었고, 2006년부터 교육과학기술부 리더연구사업 (창의)으로 지원받아 인하대에서 수행되었다. 이 연구에서는 반 도체 느린 빛이 $\mathrm{THz}$-광로직을 구성하는 필수 요구 조건인데, 2009년 고체매질에서 느린 빛 기반 NAND/NOR 광로직을 선 행 증명했고, ${ }^{[13]}$ 동시에 반도체 양자우물 구조에서 느린 빛을 최초로 증명하여, ${ }^{[14]} \mathrm{THz}$-광로직 출현이 기대되었다. 그러나 정 부 연구비 축소와 세계 연구 방향 변화로 인해 광로직 연구는 2009년 이후 사실상 중단상태이다. THz-광로직 연구에서 물리 적인 한계 돌파 원리는, 일반적으로 스위칭 속도 한계는 매질 의 밀도전이 시간으로서 반도체화합물에서는 $10 \mathrm{GHz}$ 가 그 한

\section{REFERENCES}

[1] B. S. Ham, Center for Quantum coherence and ultrafast information processing Ministry of Science and Technology, S. Korea (2000). [함병승, 양자결맞음 초고속정보통신 연구단, 과학기 술부 창의적연구진흥사업 (2000).]

[2] K.-J. Boller, A. Imamoglu and S. E. Harris, Phys. Rev. Lett. 66, 2593 (1991); M. Xiao, Y. Li, S. Jin and J. Gea-Banachoche, Phys. Rev. Lett. 74, 666 (1995); B. S. Ham, P. R. Hemmer and M. S. Shahriar, Opt. Communi. 144, 227 (1997).

[3] L. V. Hau, S. E. Harris, Z. Dutton and C. Behroozi, Nature 397, 594 (1999); M. Fleischhauer and M. D. Lukin, Phys. Rev. Lett. 84, 5094 (2000).

[4] C. Liu, Z. Cutton, C. H. Behroozi and L. V. Hau, Nature 409, 490 (2001); F. F. Philips, A. Fleischhauer, A. Aair, R. L. Walsworth and M. D. Lukin, Phys. Rev. Lett. 86, 783 (2001); O. Kocharovskaya, Y. Rostovstsev and M. O. Scully, Phys. Rev. Lett. 86, 628 (2001); A. V. Turukhin et al., Phys. Rev. Lett. 88, 023602 (2002).

[5] R. W. Boyd, Nonlinear Optics, 3rd Ed. (Academic, New York, 2008).

[6] K. Hakuta, L. Marmet and B. P. Stoicheff, Phys. Rev. Lett. 66, 596 (1991); M. Jain, H. Xia, G. Y. Yin, A. J. Merriam and S. E. Harris, Phys. Rev. Lett. 77, 4326 (1996); B. S. Ham, M. S. Shahriar and P. R. Hemmer, Opt. Lett. 22, 1138 (1997).

[7] For review paper see T. Baba, Nature Photon 2, 465 (2008).

[8] P. C. Ku, F. Sedgwick, C. J. Chang-Hasnain, P. Palinginis, T. Li and H. Wang, Opt. Lett. 29, 2291 (2004); S.-M. Ma, H. Xu and B. S. Ham, Opt. Exp. 17, 148902 (2009).

[9] A. Karalis, E. Lidorikis, M. Ibanescu, J. D. Joannopolos and M. soljacic, Phys. Rev. Lett. 95, 063901 (2005); J. Gu et al., Nat. Commus. 3, 1151 (2012).

[10] J. H. Kim, Y. M. Jhon, Y. T. Byun, S. Lee, D. H. Woo and S. H. Kim, IEEE Photonics Technol. Lett. 14, 1436 (2002).

[11] MIT-Lincoln Lab 인터넷 자료. See also, J. P. Wang, All-optical processing for ultrafast data networks using semiconductor optical amplifiers, Ph.D. thesis, MIT-Lincoln Lab. (2008).

[12] B. S. Ham, Center for Photon Information Processing, Ministry of Education, Science, and Technology, S. Korea (2006). [함 병승, 광양자정보처리연구단, 교육과학기술부 리더연구사업(창의) (2000).]

[13] B. S. Ham and J. Hahn, Appl. Phys. Lett. 94, 101110 (2009).

[14] S.-M. Ma, H. Xu and B. S. Ham, Opt. Exp. 17, 148902 (2009). 
계가 되는데, EIT에서의 양자결맞음을 이용하게 되면, 그 한 계는 위상전이시간으로 바뀌게 되어, $100 \mathrm{GHz}$ 이상도 가능함 이 증명되었다. ${ }^{[15]}$ 한편, 인텔에서 십여 년 전부터 야심차게 준 비하고 있는 실리콘포토닉스는 전자CPU는 그대로 둔 채, 칩 내(intra-chip) 혹은 칩 간(inter-chip) 통신대역폭의 한계 $(<10$ $\mathrm{GHz})$ 를 지닌 구리선을 광선 $(>100 \mathrm{GHz})$ 으로 바꾸고자 하는 시도로서 순수 광컴퓨팅으로 가는 중간단계에 다름 아니다. ${ }^{[16]}$

\section{2. 양자정보통신}

(1) 확정적 단광자 발생장치

양자정보통신은 디지털 광정보통신과는 달리, 양자신호와 그 신호의 양자중첩을 이용한다. ${ }^{[1]}$ 통신을 위해서는 기존 광정보 통신과 마찬가지로 양자정보통신도 비슷한 구성요소를 갖추어 야 하는데, 즉 송신부, 수신부, 교환부로 구성되는 네트워크 구 조를 만족해야 하는데, ${ }^{[18]}$ 현재 대부분 양자통신 프로토콜은 교 환부를 제외한 송신부와 수신부, 즉 $1: 1$ 통신에 기초한다. ${ }^{[19]}$ 따라서 현재 양자통신 시스템 구성은 매우 원시적인 모델을 따르는 초보적 단계이나, 아직 확정적 단광자 발생기조차 없는 상황이다. 또한, 단광자를 셀 수 있는 수신기도 존재하지 않을 뿐더러, 양자스위칭 개념도 제대로 정립되지 않아 셋 이상의 양자상태가 얽힌 다양자상태(GHZ)를[20] 이용하는 N:N 양자통 신은 사실상 요원하다. 비록 가야 할 길은 멀지만 무조건적 보 안을 담보하는 양자통신의 원리로 인해 세계 많은 국가들은 지난 이십 여 년 간 양자암호 연구에 막대한 투자를 지속해오 고 있으며, 최근에는 단광자 발생을 위한 결실이 하나둘 나오 고 있다. 그 대표적인 방법이 반도체 양자점에서 포톤-blockade 를 이용한 확정적 단광자 발생이다. ${ }^{[21]}$ 이 원리는 1990년대 제 안되어 ${ }^{[22]} 2000$ 년대 광범위하게 연구되었는데, 최근 부쩍 관심 을 끄는 이유는 마이크로 공진기 현실화 방안으로 나노포토닉 스와 결합하여, 예를 들면, 광격자, 표면플라즈몬 등의 분야와 결합하여 국소 확정적 단광자 발생에 대한 가능성이 고조되었 기 때문이다. ${ }^{[23]}$ 여기서 핵심적인 문제는 확정적으로 단일 양 자점의 위치를 정확히 포착하여, 그 위에 DBR(Distributed Bragg Reflector) 구조의 미세공진기를 반도체 적층구조로 구 성(혹은 그 주변에 광격자구조를 형성 $\left.{ }^{[24]}\right)$ 하는 것인데, 트럼펫 혹은 tapered 타입의 DBR 나노기술적용으로 단광자 포획율을 획기적으로 개선한 점이 최근 보도되었다. ${ }^{[25]}$ 이 분야에선 최근 중국이 상당할 정도로 추격하여 선진국과 거의 비슷한 수준에 육박한 것으로 보인다. ${ }^{[26]}$ 수년 내 양자정보 통신분야는 반도체 양자점기반 단광자 발생기 출현으로 인해 원시적 상태를 벗어 나 어느 정도 현재의 디지털 통신을 대체하며 발전할 것으로 예측된다. 두 번째 가능성으로는 whispering gallery mode에 기초한 실리카 마이크로 디스크 공진기인데, 부피가 작아지면
서 생겨나는 양자화된 빛은 매우 작아진 모드 부피로 인해 단 광자를 선택할 수 있게 된다. ${ }^{[27]}$ 이 분야 역시 1990년대부터 꾸준히 연구되어 왔고 최근 나노광학기술의 발전과 더불어 최 근 그 실현 가능성이 고조되고 있다. ${ }^{28]}$

\section{(2) 장시간 양자메모리}

앞에서 언급했듯 양자메모리 분야는 느린 빛에 기초한 멈춤 빛 연구에 의해 촉발되었다. ${ }^{[4,29]}$ 이 분야는 전통적인 원자물리 분야와 공진기양자기전(cavity-QED) 분야가 결합된 것인데, 기 본적으로 단일광자와 단일원자의 상호작용에 기초한다. 정보처 리에 있어 현실적인 파라미터는 대역폭인데, 공진기양자기전의 경우 효율과 대역폭은 반비례 관계에 놓여, 시스템 구성에 있 어 모순된 결과를 낳는다. 이로 인해, 즉 넓은 대역폭을 확보 하기 위해, 2010년대 들어와서는 단일원자 공진기 ${ }^{[30]}$ 대신 벌

\section{REFERENCES}

[15] B. S. Ham, Appl. Phys. Lett. 78, 3382 (2001); B. S. Ham and P. R. Hemmer, Phys. Rev. B 68, 073102 (2003)

[16] See http://www.intel.com/content/mww/us/en/research/intel -labs-animation-how-silicon-photonics-work-video.html.

[17] M. A. Nielsen and I. L. Chuang, Quantum computation and quantum information (Cambridge Univ., 2000).

[18] H. J. Kimble, Nature 453, 1023 (2008).

[19] C. H. Bennett and G. Brassard, Phys. Rev. A 72, 032301 (2005); N. Gisinand and R. Thew, Nat. Photon. 1, 165 (2007).

[20] D. M. Greenberger, M. A. Horne, A. Shimony and A. Zeilinger, Am. J. Phys. 58, 1131 (1990); J. W. Pan et al., Rev. Mod. Phys. 84, 777 (2012).

[21] D. Englund, A. Faraon, I. Fushman, N. Stoltz, P. Petroff and J. Vuckovic, Nat. 450, 857 (2007); D. Englund, A. Majumdar, M. Bajcsy, A. Faraon, P. Petroff and J. Vuckovic, Phys. Rev. Lett. 108, 093604 (2012); for photon blockade see K. M. Birnbaum, A. Boca, R. Miller, A. D. Boozer, T. E. Northup and H. J. Kimble, Nature 436, 87 (2005).

[22] A. Imamoglu, H. Schmidt, G. Woods and M. Deutsch, Phys. Rev. Lett. 79, 1467 (1997).

[23] K. Hennessy, et al., Nature 445, 896 (2007).

[24] T. Kojima, K. Kojima, T. Asano and S. Noda, Appl. Phys. Lett. 102, 011110 (2013).

[25] M. Munsch et al., Phys. Rev. Lett. 110, 177402 (2013); J. Claudon et al., Nature Photon. 4, 174 (2010).

[26] PIERS2014 (Session 1P2b), Guangzhou, China.

[27] P. Michler et al., Science 290, 2282 (2000); D. K. Armani, T. J. Kippenbert, S. M. Spillane and K. J. Vahala, Nature 421, 925 (2003).

[28] S. Azzini, et al., Opt. Express 20, 23100 (2012); E. Engin et al., Opt. Exp. 21, 27826 (2013)

[29] S. Choi, H. Deng, J. Laurat and H. J. Kimble, Nature 452, 67 (2008).

[30] For Nobel lectures by S. Haroche, see http://unw.college-defrance.fr/site/en-serge-haroche/research_achievements. htm\#|m=1323702380764|p=/site/en-serge-haroche/sum mary_of_research.htm. 
크 매질을 채택하게 되는데, ${ }^{[29,31]}$ 그 핵심원리는 1980년대 유 행했던 포톤에코에 기초한다. ${ }^{[32]}$ 포톤에코는 비균질 2준위 벌 크매질에 인위적인 양자결맞음을 유도하고, 유도된 각각의 원 자전이선(파)에 pi-펄스를 이용 재위상(rephasing)하는 방법으 로 에코를 획득하여 정보저장기능을 수립하는 고전적 방식이 다. 여기서 재위상은 기본적으로 매질 내 밀도반전에 기초하는 데, 이때 필연적으로 발생하게 되는 자발방출이나 유도방출은 단일광자를 사용하는 양자 정보처리에 있어 치명적인 한계가 된다. 이로 인해, 포톤에코 자체는 양자메모리에 적용할 수 없 는데, 2010년대에 들어 이를 극복할 몇 가지 방법이 제시되었 다. 그 대표적인 경우가 제네바대학에서 제기한 원자주파수빗 $(\mathrm{AFC})$ 방식이고, 최근에는 양자메모리가 증명되기도 하였다. ${ }^{[3]}$ 일반적으로 양자 정보처리를 위해서는 양자효율이 $90 \%$ 이상 이 되어야 하나, $\mathrm{AFC}$ 양자메모리에 있어 양자메모리 효율은 $50 \%$ 이하이다. 한편, $\mathrm{AFC}$ 는 광준위계를 이용하는 특성상 저 장시간은 만분의 일초 수준이다. $\mathrm{AFC}$ 의 낮은 재생효율을 극복 하기 위해 원자공진기 사용이 제시되었으나 앞서 언급한 주파 수대역 희생을 감수해야만 한다. 기본적으로 글로벌 양자네트 워크 구현에 있어 양자리피터는 필수 양자하드웨어가 되는 데, ${ }^{[34]}$ 양자리피터는 두 개의 양자노드간 양자얽힘 교환을 담당 하는 소자이고, 이를 위해서는 양자메모리가 핵심소자가 된 다. ${ }^{[3]}$ 이때, 전송거리는 양자메모리 저장시간에 로그 스케일 로 증가하는데, $500 \mathrm{~km}$ 양자전송을 위해 필요로 하는 양자메 모리 저장시간은 100 초 이상이다 ${ }^{[35]}$ (초기 DLCZ(Duan-LukinCirac-Zoller) protocol을 적용시켰을 경우). 이를 만족하는 유 일한 양자메모리 프로토콜은 교과부 리더연구사업에서 ${ }^{[12]}$ 산출한 광잠금방식인데, ${ }^{[36]}$ 최근 그 선행연구도 증명하여 양자상태를 직접 적용하기 위한 가능성은 기정사실화되어 있다. ${ }^{[3]}$ 그러나 궁극적으로 벌크형태의 냉각기체나 고체매질은 시스템 구성측 면에서 볼 때 지양되어야 하고, 이를 실제적으로 구현하기 위 해서는 나노포토닉스 기술 적용이 요청되는데, 위에서 언급한 광 격자구조 등이 적용될 것으로 예측된다. ${ }^{[3]}$ 이 연구, 즉 확장적 (scalable) 나노양자메모리를 위해 광주과학기술원과 Caltech의 국제공동연구가 곧 수행될 예정이다.

\section{결 론}

이상 반도체기반 광정보 처리 분야에 있어, 그의 고전적 영역 과 양자분야에 대해 고찰하였는데, 반도체광소자, 광격자, $\mathrm{Si}$ 나 노포토닉스 등 보다 대중적인 분야는 본 고찰에서 제외하였고, 잘 알려지지 않은 국소 분야에 집중했다. 그 이유는 이 국소 분 야에 주어지는 미래지향성 때문이다. 이에 대한 판단근거로는, 광정보처리의 핵심은 빛만을 매개로 하는 순수 광로직과 그에 기초한 광연산장치 즉 광컴퓨터에 있기 때문이고, 이와는 별도 로 현재 고전적 연산장치나 통신으로는 해결할 수 없는 특수한 영역 즉 양자정보 처리/양자정보 통신에는 보다 먼 미래를 견 인할 특징이 있기 때문이다. 특히 요즘과 같이 개인정보 유출이 사회적 문제로 대두되고 있는 시기에 있어, 무조건적 보안을 특 징으로 하는 양자암호 통신은, 핵심적인 양자소자 구현의 문제 가 있음에도 불구하고(예를 들면 확정적 단광자/얽힘쌍 발생장 치, 양자메모리, 양자스위치, 양자리피터, 광자수 식별검출기 등), 최근 양자점을 이용한 얽힘광자쌍 구현이 현실화되는 점을 고려한다면, ${ }^{[39]}$ 그 실현시기가 한층 앞당겨질 수도 있을 것으로 예상된다.

\section{REFERENCES}

[31] C. Clausen et al., Nature 469, 508 (2011); M. Hosseini et al., Nat. Physics 7, 794 (2011); T. Peyronel et al., Nature 488, 57 (2012)

[32] N. A. Kurnit, I. D. Abella and S. R. Hartmann, Phys. Rev. Lett. 13, 567 (1964)

[33] M. Afzelius et al., Phys. Rev. Lett. 104, 040503 (2010).

[34] L.-M. Duan, M. D. Lukin, J. I. Cirac and P. Zoller, Nature 414, 413 (2001).

[35] N. Sangouard, C. Simon, H. de Riedmatten and N. Gisin, Rev. Mod. Phys. 83, 33 (2011).

[36] B. S. Ham, Nat. Photon. 3, 518 (2009); Ibid, Phys. Rev. A 85, 031402 (2012)

[37] B. S. Ham, New J. Phys. 14, 013003 (2012).

[38] D. L. McAuslan, D. Korystov and J. J. Longdell, Phys. Rev. A 83, 063847 (2011); A. Faraon et al., Phys. Rev. Lett. 109, 033604 (2012)

[39] A. Dousse et al., Nature 466, 217 (2010); M. Muller, S. Bounouar, K. D. Jons, M. Glassl and P. Michler, Nat. Photon. 8, 224 (2014). 